\title{
MANEJO DA PALHA DA AVEIA PRETA SOBRE A CULTURA DA SOJA EM \\ SEMEADURA DIRETA
}

\section{MANAGEMENT OF BLACK OAT STRAW ON DIRECT SOWING SOYBEAN CROP}

\author{
Jean Francisco dos SANTOS ${ }^{1}$ Willian Junior PARTICA NOGARA², Marluce \\ GONÇALVES CORTEZ ${ }^{3}$, Silvana OHSE ${ }^{3}$
}

1 - Engenheiro Agrônomo, Empresa Grão Limpo. Vila Vendrami, Ponta Grossa - PR.

2 - Engenheiro Agrônomo, Forquímica Agriciência LTDA - Centro De Distribuição, Petrópolis, Passo Fundo RS, Brasil.

3 - Docentes do Departamento de Fitotecnia e Fitossanidade, Curso de Agronomia - Universidade Estadual de Ponta Grossa, Ponta Grossa/PR.

Autor para correspondência: contato@graolimpo.com.br

\section{RESUMO:}

A cultura da aveia preta é utilizada como cobertura do solo durante o inverno em área expressiva dos Campos Gerais/Paraná. Assim, conduziu-se um experimento em blocos casualizados com 4 repetições, constando de 3 níveis do fator época de dessecação da aveia preta (30, 15 e 0 dias antes da semeadura-DAS) e 3 níveis do fator manejo mecânico da palha (rolagem longitudinal, transversal e ausência de rolagem), com objetivo de avaliar o efeito destes fatores sobre o desenvolvimento das plantas daninhas e da cultura da soja, cultivar CD-205. Não houve interação entre os fatores para nenhuma das variáveis avaliadas. A época de dessecação da aveia preta influenciou o teor de água no solo, o qual foi maior quando realizada aos 30 DAS; a densidade de plantas daninhas, com menores valores quando da dessecação aos 15 DAS e a estatura da cultura da soja em R7, aos 30 DAS, não repercutindo em produtividade. A rolagem da palha de aveia preta no sentido transversal e ausência de rolagem tiveram efeito supressivo sobre o desenvolvimento das plantas daninhas, denotado pela maior cobertura do solo, menores valores de massa fresca e seca, reduzindo a competição interespecífica, beneficiando a cultura da soja, a qual produziu 18,43 e $15,32 \%$ a mais que quando da rolagem no sentido Longitudinal, respectivamente. Conclui-se que, para estas condições, o mais econômico é não rolar a aveia preta, minimizando gastos com mão de obra, combustível, depreciação de equipamentos, reduzindo com isso, a compactação e desagregação do solo, independentemente da época de dessecação.

Palavras-chave: Glycine max L., Avena strigosa Schreb., plantio direto, época de dessecação.

\section{ABSTRACT:}

Being the culture of oats used as ground cover during the winter in a significant area of Campos Gerais/Paraná. Thus, a randomized block experiment with 4 replications was carried out, consisting of 3 levels of the black oat desiccation time factor (30,15 and 0 days before sowing-DAS) and 3 levels of the mechanical straw management factor (rolling longitudinal, transverse and no-rolling), with the objective to evaluate the effects of these factors on weed and soybean crop development, CD-205 cultivar. There was no interaction between the factors for any of the evaluated variables. Black oat desiccation time influenced soil water content, which was higher when performed at 30 DAS; weed density, with lower values when desiccated at 15 DAS and soybean crop height at R7 at 30 DAS, not affecting the yield. Rolling of black oat straw in the transverse direction and absence of rolling had a 
suppressive effect on weed development, denoted by higher soil cover, lower fresh and dry mass values, reducing interspecific competition, benefiting soybean crop, which produced $18.43 \%$ and $15.32 \%$ more than when rolling in the Longitudinal direction, respectively. It is concluded that, for these conditions, the most economical is not to roll the black oats, minimizing labor, fuel, equipment depreciation, reducing the compaction and disintegration of the soil, regardless of the black oat desiccation time.

Key words: Glycine max L., Avena strigosa Schreb., no-till, desiccation season.

\section{INTRODUÇÃO}

A soja (Glycine max L.) é o produto agrícola de maior expressão econômica no Brasil, além de ser o principal produto de exportação do agronegócio brasileiro para os mais diversificados fins, garante a demanda interna para a produção de, entre outros produtos, óleo, farelo, lecitina entre outros (HIRAKURI; LAZZAROTTO, 2014). O Brasil é, segundo o Departamento de Agricultura Americano - USDA, o maior exportador mundial de soja $(44,68 \%)$ e também o maior produtor mundial com 33\% do total produzido mundialmente, tendo ultrapassado os Estados Unidos (32,85\%) neste último quesito (USDA, 2019). O Brasil e os EUA juntamente com a Argentina (15,80\%) são responsáveis por 81,65\% da produção mundial e por $88,13 \%$ das exportações mundiais da cultura (CONAB, 2019). Destacando-se dentro do cenário produtivo nacional as regiões Centro-sul, onde o estado do Mato Grosso é o maior produtor, e a região Sul com os estados do Rio Grande do Sul e Paraná, apresentando produção acima de 18 e 16 milhões de toneladas, respectivamente e produtividades acima de $3000 \mathrm{~kg}$ ha-1 (CONAB, 2019). Os bons resultados econômicos alcançados com a cultura têm estimulado os produtores a investirem cada vez mais na utilização de técnicas avançadas de manejo de pragas, patógenos e plantas daninhas.

O desenvolvimento das culturas pode ser limitado por plantas que infestam áreas agrícolas, pecuárias e de outros setores do interesse humano, denominadas daninhas (PITELLI, 2015). A depender da densidade, da espécie de planta daninha e da época em que a competição se estabelece, a produtividade das culturas agrícolas pode ser significativamente reduzida, o que segundo Lorenzi (2006), gira em torno de 30 a 40\%. Os prejuízos na cultura da soja variam de acordo com as espécies infestantes existentes na área durante o desenvolvimento da cultura, com o cultivar e com a intensidade da interferência a que cultura é submetida (BORTOLUZZI; ELTZ, 2001; VOLL et al., 2002; RIZZARDI et al., 2004; NEPOMUCENO et al., 2007; PITELLI, 2015).

A cobertura do solo funciona como elemento isolante reduzindo a amplitude térmica do solo, auxiliando na manutenção da água no solo, filtrando a radiação solar e reduzindo o impacto das gostas. O processo de germinação de sementes de plantas daninhas do 
grupo das fotoblásticas positivas está intimamente relacionado a estes fatores, reduzindo substancialmente sua emergência em semeadura direta em presença de abundante quantidade de cobertura morta (BORGES et al., 2014). Em muitos casos, a época de emergência das plantas daninhas em relação à cultura representa o fator mais importante para definir seu potencial competitivo do que, até mesmo, a própria densidade de indivíduos. Dessa maneira, o intervalo entre a dessecação da cobertura vegetal e a semeadura da soja, constitui-se em fator crítico e desempenha papel primordial na análise econômica do controle, devido à sua influência sobre a infestação das plantas daninhas (RIZZARDI et al., 2003; RIZZARDI et al., 2004). Assim como a época de semeadura da cultura, após a dessecação da cobertura vegetal antecessora, no sistema de semeadura direta, pode influenciar na competitividade com as plantas daninhas (BORGES et al., 2014).

Considerando a relevante competição interespecífica entre plantas daninhas e culturas de interesse, há necessidade de se utilizar diferentes métodos de controle de plantas daninhas, visando minimizar ou mesmo, extinguir a interferência causada na cultura da soja. Com a expansão da técnica de semeadura direta na Região nos Campos Gerais/PR, desde 1980, torna-se incontestável o estudo e desenvolvimento de estratégias que aliem a cobertura de solo ao controle químico, reduzindo assim, o efeito da competição por água, luz, nutrientes, CO2 e espaço físico entre plantas daninhas e a cultura da soja. Neste contexto, o trabalho fundamentou-se na hipótese de que o manejo mecânico associado ao manejo químico da palha da aveia preta pode ocasionar modificações, tanto na ocorrência como no desenvolvimento da comunidade de plantas daninhas, bem como sobre o desenvolvimento e produtividade da cultura da soja.

\section{MATERIAL E MÉTODOS}

O experimento foi conduzido na "Fazenda Escola Capão da Onça", situada à Rodovia PR-513, Ponta Grossa/Paraná-Brasil, à latitude de 2505'47" sul e 5003'11' a oeste. A região tem o clima classificado como $\mathrm{Cfb}$ subtropical úmido mesotérmico, conforme classificação de Köppen (PEEL et al., 2007) e o relevo do local é suave ondulado, com solo classificado como Cambissolo Háplico Distrófico de textura média (EMBRAPA, 2006). As propriedades físico-químicas da área $(0-20 \mathrm{~cm})$ constaram de 3,82\% de M.O.; $\mathrm{pH} \mathrm{CaCl} 2$ de 5,2; 18,1 mg dm-3 de P; 0,36; 3,5; 1,7; 3,69 e 9,25 cmolc dm-3 de K+; Ca+2; Mg+2; $\mathrm{H}++\mathrm{Al}+3$ e CTC, respectivamente e V\% de 60,1.

A soja, cultivar CD-205, teve sua semeadura efetuada em 8 de novembro de 2006, 
realizada com semeadora de precisão de uso múltiplo modelo SSM, a qual distribuiu 16 sementes por metro, em espaçamento entre linhas de $0,45 \mathrm{~m}$ e profundidade de 3 a $5 \mathrm{~cm}$. As sementes foram inoculadas com Bradyrhizobium sp. e tratadas com a mistura comercial de fungicidas fludioxonil + metalaxyl-M na dose de $35 \mathrm{~g}+10 \mathrm{~g}$ por $100 \mathrm{~kg}$ de sementes e 0 inseticida fipronil na dose de $50 \mathrm{~g}$ por $100 \mathrm{~kg}$ de sementes. Simultaneamente a operação de semeadura foi realizada a adubação no sulco de semeadura na dosagem $300 \mathrm{~kg}$ ha-1 de NPK da formulação 4-20-20.

O experimento foi conduzido em blocos ao acaso, em arranjo fatorial $3 \times 3$, com quatro repetições, perfazendo um total de 36 parcelas, apresentando área total de $20 \mathrm{~m}^{2}(5$ x $4 \mathrm{~m}$ ) e área útil de $9 \mathrm{~m}^{2}(3 \times 3 \mathrm{~m})$. Os tratamentos eram compostos de três épocas de dessecação em pré-semeadura da aveia preta (30, 15 e 0 dias antes da semeadura [DAS] da cultura da soja), e três diferentes manejos da palha (rolagem longitudinal e transversal ao sentido de semeadura da aveia preta e ausência de rolagem).

A dessecação, nas três épocas, foi realizada com o herbicida glyphosate (Roundup Transorb(C), na dose de $960 \mathrm{~g}$ do i.a. ha-1, o que equivale a $2 \mathrm{~L}$ ha-1 do produto comercial, provido de barra com 2 m e 4 bicos com pontas de jato em leque 110.02 e volume de calda de $200 \mathrm{~L}$ ha-1. As aplicações foram feitas com pulverizador costal, à pressão de 26 psi por CO2 comprimido, provido de barra com 2 metros e 4 bicos com pontas de jato em leque 110.02 e volume de calda de $200 \mathrm{~L}$ ha-1. As aplicações foram realizadas nos dias 10 e 24 de outubro (30 e 15 DAS) e 08 de novembro (0 DAS). A cobertura de palha na gleba foi de $22.500 \mathrm{~kg}$ ha-1 de massa fresca e $6.900 \mathrm{~kg}$ ha-1 de massa seca. No dia da semeadura foi efetuada a rolagem da palha nos tratamentos em que essa era necessária, a qual foi efetuada com rolo faca, seis horas após a última aplicação do dessecante.

Aos 3 dias depois da semeadura (DDS) verificou-se a qualidade de cobertura da palha, lançando-se aleatoriamente sobre a área útil da parcela uma haste com pontos marcados espaçados $10 \mathrm{~cm}$ uns dos outros, verificando-se, em seguida se os locais onde esses pontos marcados tocavam o solo estavam ou não cobertos por palha. Essa operação foi repetida 4 vezes, calculando-se posteriormente a porcentagem de pontos cobertos e não cobertos. Foram feitas avaliações da infestação de plantas daninhas aos 15, 28 e 35 DDS, através de contagens, diferenciando as infestantes por espécies. Aos 35 DDS foram determinadas as massas frescas e secas de plantas daninhas. Ambas as medições foram feitas com 4 amostras de 0,0625 $\mathrm{m}^{2}$ em cada parcela.

Em relação à cultura da soja foram avaliados: Índice de velocidade de emergência: aos 7 DDS iniciaram-se as avaliações diárias do número de plântulas emergidas em um 
metro de linha demarcado na área útil da parcela, conforme metodologia proposta por Maguire (1962). Estande inicial: foi realizada contagem de plântulas emergidas em um metro de linha dentro da área útil aos 20 DDS quando da estabilização da emergência. Estande final: correspondeu ao número de plantas em um metro de linha da área útil no momento da colheita. Altura de plantas, número de nós e número de vagens por planta: realizados no estádio $\mathrm{R} 7$ (maturação fisiológica), amostrando-se 10 plantas na área útil de cada parcela. Aos 135 DDS, a soja foi colhida na área útil de cada parcela, determinandose a produtividade e massa de 1000 grãos, padronizando-se a umidade em 14\% b.u.

Aos 40 DDS foi feita aplicação do herbicida bentazon (720 g i.a. ha-1) para o controle das plantas daninhas de folha larga e chletodim + fenoxaprop-P-ethyl (50 g de cada i.a. ha-1) para o controle das plantas daninhas de folha estreita. Esse controle foi efetuado a fim de se conduzir a cultura livre do efeito da competição pelas plantas daninhas, e facilitar a colheita. O controle de pragas e doenças quando necessário.

Os dados obtidos para cada variável foram analisados estatisticamente através da aplicação da análise da variância pelo teste de $F$. Para as variáveis com valores de $F$ significativos, procedeu-se a aplicação do teste Tukey para comparação das médias, ao nível de 5\%. Quando de interação entre os fatores, realizou-se o desdobramento do fator época de dessecação da palha de aveia preta dentro do fator tipo de manejo da palha da aveia preta. O programa estatístico utilizado foi o Assistat 7.7 beta (SILVA; AZEVEDO, 2009).

\section{RESULTADOS E DISCUSSÃO}

A análise da variância não revelou interação entre épocas de dessecação e sentido de rolagem da palha de aveia preta para nenhuma das variáveis analisadas, ou seja, o manejo mecânico associado ao manejo químico da palha da aveia preta não ocasionou modificações na ocorrência e desenvolvimento da comunidade de plantas daninhas, nem no desenvolvimento e produtividade da cultura da soja, cultivar CD-205. Entretanto, houve efeito significativo do manejo mecânico da palha de aveia preta para a variável cobertura do solo. A porcentagem de cobertura do solo propiciada pela palha de aveia preta variou entre 58,8 e 75\%, sendo que a rolagem da aveia preta no sentido longitudinal foi 0 tratamento que proporcionou menor cobertura do solo, resultando em média 21,6 e 17,2\% a menos de área coberta pela palha da aveia preta que nas unidades experimentais onde se utilizou o rolamento transversal e não se rolou a cultura da aveia preta, respectivamente, 
independentemente da época de dessecação (Tabela 1). De acordo com Boller; Caldato (2001), qualquer sistema de preparo do solo e de semeadura que mantenha no mínimo $30 \%$ da superfície do solo coberta por resíduos, entre a colheita da cultura anterior até logo após a implantação da cultura seguinte, denomina-se manejo conservacionista. Da mesma forma Ceretta et al. (2002) ratificam que a manutenção de elevada quantidade de palha e porcentagem de cobertura na superfície do solo é fundamental para a sustentabilidade do Sistema Plantio Direto. Assim, a cobertura do solo proporcionada pela palha da cultura de aveia preta, neste estudo, é uma boa opção para o manejo conservacionista da área agrícola em questão (Tabela 1).

Tabela 1. Cobertura de palha de aveia preta na área experimental e índice de velocidade de emergência de plântulas da soja (IVE), cV. CD-205, em função da época de dessecação e do tipo de rolagem da palha de aveia preta. UEPG, Ponta Grossa-PR.

\begin{tabular}{|c|c|c|c|c|c|c|c|c|}
\hline \multirow{3}{*}{$\begin{array}{l}\text { Épocas de } \\
\text { Dessecação }\end{array}$} & \multicolumn{3}{|c|}{ Cobertura de palha (\%) } & \multicolumn{5}{|c|}{ IVE (plântulas dia-1 } \\
\hline & \multicolumn{3}{|c|}{ Rolagem } & MÉDIAS & \multicolumn{3}{|c|}{ Rolagem } & \multirow[t]{2}{*}{ MÉDIAS } \\
\hline & Longit. & Transv. & S. rol. & & Longit. & Transv. & S. rol. & \\
\hline $30 \mathrm{DAS}^{1}$ & 55,5 & 79,5 & 68,0 & $67,7 \mathrm{a}$ & 1,7 & 1,4 & 1,7 & $1,6 \mathrm{a}$ \\
\hline 15 DAS & 62,5 & 73,0 & 76,0 & $70,5 \mathrm{a}$ & 1,7 & 1,7 & 1,7 & $1,7 \mathrm{a}$ \\
\hline 0 DAS & 58,5 & 72,5 & 69,5 & $66,8 \mathrm{a}$ & 1,8 & 2,0 & 1,9 & $1,9 a$ \\
\hline MÉDIAS & $58,8 \mathrm{~B}$ & $75,0 \mathrm{~A}$ & $71,0 \mathrm{~A}$ & & $1,7 \mathrm{~A}$ & $1,7 \mathrm{~A}$ & $1,8 \mathrm{~A}$ & \\
\hline CV (\%) & & 11,98 & & & & 20,04 & & \\
\hline
\end{tabular}

${ }_{1}^{1}$ DAS = dias antes da semeadura da soja. Longit.= Longitudinal; Transv.= Transversal; S. rol.= Sem rolagem. ${ }_{2}^{2}$ Médias seguidas da mesma letra minúscula, comparadas na coluna, e letra maiúscula, na linha, não diferem entre si pelo teste de Tukey $(P>0.05)$.

Quando da avaliação aos 20 dia após a aplicação dos tratamentos (DAAT), Bortoluzzi; Eltz (2000) obtiveram, quando da ausência de rolagem, ou seja, palha da aveia preta em pé $96,7 \%$ de cobertura do solo e, quando da rolagem da palha $90,8 \%$. Todavia, quando da avaliação aos 30 DAAT observaram valores médios de 81,1 e 74,0\%, nesta ordem, de cobertura do solo. Valores estes superiores ao valor médio obtido quando da rolagem longitudinal da aveia preta, encontrando-se, porém, mais próximos aos valores obtidos quando da rolagem transversal e ausência de rolagem da aveia preta, independentemente da época de dessecação (Tabela 1).

A menor eficiência na cobertura de solo no sistema de manejo com rolagem longitudinal provavelmente esteja relacionada ao fato de que o rolo faca atua tombando e cortando a palha de aveia preta e, consequentemente, depositando os fragmentos em 
sentido paralelo ao sentido de atuação dos discos da semeadora utilizada na semeadura da soja, podendo arrastar a palha sem cortá-la efetiva e eficientemente, fazendo com que a área, principalmente próxima à linha de semeadura, ficasse descoberta.

Os fatores época de dessecação e sistemas de manejo mecânico da palha de aveia preta não aceleraram a emergência das plântulas de soja, medida pelo índice de velocidade de emergência (IVE), mesmo considerando o estímulo que a cobertura do solo pode promover a esta variável, apresentando média de 1,7 plântulas dia-1 (Tabela 1). Pode-se atribuir a ausência de diferença entre o IVE em função dos tratamentos aplicados, ao fato do solo apresentar boa disponibilidade de água na fase de germinação e emergência da cultura, devido à boa precipitação pluviométrica nesse período, bem como temperaturas favoráveis à germinação, as quais giraram em torno de 25ํㅡ. Bortoluzzi; Eltz (2000) também não encontraram diferenças para a variável IVE da cultura da soja independentemente do manejo da palha de aveia testado, contudo detectaram menor IVE quando da ausência de palha e de plantas daninhas. Boller; Caldato (2001), estudando coberturas de solo (centeio, nabo forrageiro, centeio + nabo forrageiro e pousio mantido sem vegetação no inverno) associadas a sistemas de preparo do solo (convencional, reduzido e plantio direto) também não obtiveram diferença para esta variável. Semelhantemente, Leite et al. (2013) não observaram diferenças na percentagem de emergência e no IVE de feijão em função do sistema de manejo do solo utilizado (Semeadura convencional; Cultivo mínimo e Semeadura direta). Os resultados reafirmam que, a eficiência na semeadura reduz significativamente a necessidade de operações de preparo secundário, as quais podem causar compactação e desagregação do solo.

Não houve interação entre os fatores manejo mecânico da palha e época de manejo químico da aveia preta em pré-semeadura da soja para a variável teor de água no solo (Tabela 2). O teor de água no solo foi aproximadamente 14,7\% maior quando da dessecação realizada aos 30 dias antes da semeadura (DAS) em relação à dessecação realizada aos 15 DAS e no dia da semeadura da soja (Tabela 2). Resultado que pode ser outorgado ao fato da palha estar em estádio mais avançado de decomposição, ou seja, maior transformação da palha em matéria orgânica do solo, aumentando a capacidade de retenção de água. Neste contexto, Santos et al. (2015) concluíram que a cultura da aveiapreta é eficiente em manter o teor de água do solo elevado, sugerindo que essa sucessão 
de culturas possa beneficiar a produtividade da soja.

Tabela 2. Teor de água no solo após a semeadura da cultura da soja e número de plantas daninhas (NPD) emergidas por unidade de área aos 15, 28 e 35 dias após a emergência da soja (DAE), em função da época de dessecação e do tipo de rolagem da aveia preta. Ponta Grossa, UEPG.

\begin{tabular}{|c|c|c|c|c|c|c|c|}
\hline \multirow{2}{*}{$\begin{array}{l}\text { Épocas de } \\
\text { Dessecação }\end{array}$} & \multicolumn{3}{|c|}{ Teor de água no solo (\%) } & \multirow{2}{*}{ MÉDIAS } & \multicolumn{3}{|c|}{ NPD (plantas $\mathrm{m}^{-2}$ ) } \\
\hline & Longit. ${ }^{1}$ & Transv. & Sem rol. & & $15 \mathrm{DAE}^{2}$ & $28 \mathrm{DAE}$ & 35 DAE \\
\hline 30 DAS $^{1}$ & 22,89 & 22,10 & 23,25 & $22,75 \mathrm{a}$ & $179,3 \mathrm{ab}$ & $228,0 \mathrm{ab}$ & $162,0 \mathrm{ab}$ \\
\hline 15 DAS & 19,87 & 18,66 & 19,71 & $19,41 \mathrm{~b}$ & $110,0 \mathrm{~b}$ & $94,0 \mathrm{~b}$ & $131,3 b$ \\
\hline 0 DAS & 19,69 & 19,26 & 19,27 & $19,41 \mathrm{~b}$ & $199,3 \mathrm{a}$ & 255,0 a & $187,3 \mathrm{a}$ \\
\hline MÉDIAS & $20,82 \mathrm{~A}$ & $20,01 \mathrm{~A}$ & $20,7 \mathrm{~A}$ & & 162,9 & 192,3 & 160,2 \\
\hline CV (\%) & & 5,20 & & & 31,57 & 18,21 & 15,87 \\
\hline
\end{tabular}

Médias seguidas da mesma letra minúscula, comparadas na coluna, e letra maiúscula, comparadas na linha, não diferem estatisticamente entre si pelo teste de Tukey $(P>0.05)$.

${ }_{1}^{1}$ DAS $=$ dias antes da semeadura da soja. Longit.= Longitudinal; Transv. $=$ Transversal; Sem rol. $=$ Sem rolagem .

2 DAE = dias após a emergência da soja.

O resultado da análise da variância para a variável número de plantas daninhas emergidas por unidade de área (NPD) não denotou efeito significativo da interação entre os fatores estudados, nem efeito significativo do tipo de rolagem da palha de aveia preta, entretanto demonstrou efeito para o fator época de dessecação da aveia preta em todas as datas como observado na Tabela 2. O NPD foi menor em média 44,81; 63,14 e 30,06\% quando da dessecação da aveia preta aos 15 dias antes da semeadura da soja (DAS) em relação à dessecação efetuada no dia da semeadura da cultura da soja (0 DAS) nas determinações realizadas aos 15; 28 e 35 dias após a emergência da soja (DAE), respectivamente, não diferindo, no entanto, dos valores encontrados quando da dessecação realizada aos 30 DAS (Tabela 2). Vale relatar que as principais espécies daninhas presentes na área experimental durante o desenvolvimento da cultura de soja foram: papuã (Brachiaria plantaginea), picão-preto (Bidens pilosa) e picão branco (Galinsoga parviflora).

Bortoluzzi; Eltz (2000) não detectaram diferenças quanto à densidade de plantas daninhas quando da avaliação aos 15 dias após a semeadura da soja quando submetida a diferentes manejos da palhada da aveia preta (palha picada e distribuída uniformemente sobre a unidade experimental; palha em pé; palha rolada; palha gradeada; palha roçada e sem palha, com invasoras), não obstante, obtiveram valor médio de 165 plantas m-2, valor 
este muito próximo ao obtido neste experimento (162,9 plantas m-2), para a mesma época de avaliação (Tabela 2). Excepcionalmente, Ruedell (1994) tenha verificado redução significativa do NPD com o manejo mecânico da palha utilizando rolagem, em relação à ausência de rolagem. O manejo da palha pode não ter influenciado o NPD pela facilidade que as sementes de plantas daninhas encontraram para germinar e emergir em solo úmido (Blanco; Blanco, 1991), principalmente as localizadas próximo à superfície do solo, uma vez que, a precipitação pluviométrica foi alta durante todo o ciclo da cultura da soja.

As variáveis massas fresca (MFPD) e seca de plantas daninhas (MSPD) não foram influenciadas pela época de dessecação da aveia preta, entretanto, a rolagem da aveia preta no sentido longitudinal intensificou o desenvolvimento das plantas daninhas, posto que a MFPD quando deste manejo foi 128,9 e 308,6\% e a MSPD foi 127,9 e $173,5 \%$ maiores que os valores obtidos quando dos manejos rolagem transversal e ausência de rolagem da aveia preta, respectivamente. A MFPD quando do não rolamento da aveia preta foi $112 \%$ menor que quando da rolagem transversal, traduzindo-se em diferença não significativa quando seca (16,7\%) (Tabela 3). Este resultado reafirma que, a rolagem da aveia preta no sentido da semeadura da soja pode ter permitido maior incidência de luz sobre a superfície do solo, maximizando a germinação e desenvolvimento das plantas daninhas, principalmente das espécies mais populosas (G. parviflora, B. pilosa e B. plantaginea).

Tabela 3. Massa fresca (MFPD) e massa seca (MSPD) de plantas daninhas aos 40 dias após a emergência (DAE) da cultura da soja em função da época de dessecação e do tipo de rolagem da aveia preta. UEPG, Ponta Grossa-PR.

\begin{tabular}{|c|c|c|c|c|c|c|c|c|}
\hline \multirow{3}{*}{$\begin{array}{l}\text { Épocas de } \\
\text { Dessecação }\end{array}$} & \multicolumn{3}{|c|}{$\operatorname{MFPD}^{3,4}\left(\mathrm{~g} \mathrm{~m}^{-2}\right)$} & \multicolumn{4}{|c|}{$\mathrm{MSPD}^{3,4}\left(\mathrm{~g} \mathrm{~m}^{-2}\right)$} & \multirow{3}{*}{ MÉDIAS² } \\
\hline & \multicolumn{3}{|c|}{ Rolagem } & \multirow[t]{2}{*}{ MÉDIAS } & \multicolumn{3}{|c|}{ Rolagem } & \\
\hline & Longit. & Transv. & S. rol. & & Longit. & Transv. & S. rol. & \\
\hline 30 DAS $^{1}$ & 1579,27 & 699,60 & 427,25 & $902,0 \mathrm{a}$ & 264,39 & 115,35 & 74,30 & $151,35 \mathrm{a}$ \\
\hline 15 DAS & 1871,43 & 848,56 & 411,28 & $1043,8 \mathrm{a}$ & 287,64 & 123,88 & 160,02 & $190,51 \mathrm{a}$ \\
\hline 0 DAS & 2318,42 & 972,19 & 573,12 & $1287,9 \mathrm{a}$ & 357,97 & 160,02 & 98,41 & $205,47 a$ \\
\hline MÉDIAS & $1923,0 \mathrm{~A}$ & $840,1 \mathrm{~B}$ & $470,6 \mathrm{C}$ & & $303,3 \mathrm{~A}$ & $133,1 \mathrm{~B}$ & $110,9 B$ & \\
\hline CV (\%) & & 25,27 & & & & 30,84 & & \\
\hline
\end{tabular}

${ }_{1}$ DAS = dias antes da semeadura da soja. Longit.= Longitudinal; Transv. $=$ Transversal; S. rol.= Sem rolagem.

2 Médias seguidas da mesma letra minúscula, comparadas na coluna, e letra maiúscula, comparadas na linha, não diferem estatisticamente entre si pelo teste de Tukey $(P>0.05)$.

3 Infestação composta de: $39,6 \%$ de G. parviflora.; $12,8 \%$ de B. pilosa ; 47,6 \% de B. plantaginea.

${ }^{4}$ ANAVA realizada com os dados transformados para $\sqrt{ } x+1,5$ 
A massa seca de plantas daninhas (MSPD), segundo Cunha et al. (1997), oferece um indicativo de sua interferência sobre as culturas, e segundo Durigan et al. (1983) há correlação linear negativa entre MSPD e a produtividade de grãos de soja. Deste modo, os manejos rolagem transversal ao sentido de semeadura e sem rolagem, demonstraram maior capacidade em evitar o acúmulo de MSPD, apesar de não terem mostrado diferença significativas entre si em termos quantitativos, o que pode ser atribuído ao alto coeficiente de variação, o que pode ser observado na Tabela 3. O resultado ratifica os resultados encontrados por Vidal; Merotto (2001), os quais afirmam que o nível de resíduo vegetal e a conformação da palha através do manejo da mesma, influenciam o nível de supressão, pois atuam reduzindo principalmente porte das plantas infestantes. Argenta et al. (2001) observaram redução na massa seca de aveia-preta dessecada com glyphosate, na ordem de $26,8 \%$ em 15 dias após a aplicação.

O manejo mecânico da palha da aveia preta não interferiu na estatura da cultura da soja determinada no estádio R7 (maturação fisiológica), no entanto, quando do manejo químico antecipado em 30 dias em relação à semeadura da soja (30 DAS), a estatura da soja foi 3,2\% superior a quando da dessecação aos 15 DAS, não diferindo da estatura quando da dessecação no dia da semeadura (0 DAS) (Tabela 4). Riquetti et al. (2012) ao estudarem diferentes manejos mecânicos da palhada da aveia preta sobre a variável estatura de plantas de milho também não observaram diferenças significativas.

Tabela 4. Estatura de plantas na maturação fisiológica e número de nós na haste principal da soja (NNHP), cv. CD-205, em função da época de dessecação e do tipo de rolagem da aveia preta. UEPG, Ponta Grossa-PR.

\begin{tabular}{|c|c|c|c|c|c|c|c|c|}
\hline \multirow{3}{*}{$\begin{array}{l}\text { Épocas de } \\
\text { Dessecação }\end{array}$} & \multicolumn{3}{|c|}{ Estatura da soja $(\mathrm{cm})$} & \multicolumn{4}{|c|}{ NNHP } & \multirow{3}{*}{ MÉDIAS } \\
\hline & \multicolumn{3}{|c|}{ Rolagem } & \multirow[t]{2}{*}{ MÉDIAS } & \multicolumn{3}{|c|}{ Rolagem } & \\
\hline & Longit. & Transv. & S. rol. & & Longit. & Transv. & S. rol. & \\
\hline $30 \mathrm{DAS}^{1}$ & 147,8 & 150,4 & 143,7 & $147,3 \mathrm{a}$ & 16,8 & 16,8 & 17,3 & $16,9 \mathrm{a}$ \\
\hline 15 DAS & 143,6 & 142,5 & 141,8 & $142,6 b$ & 17,2 & 16,6 & 16,6 & $16,8 \mathrm{a}$ \\
\hline 0 DAS & 143,1 & 143,3 & 144,6 & $143,6 a b$ & 17,1 & 16,6 & 17,1 & $16,9 \mathrm{a}$ \\
\hline MÉDIAS & $144,8 \mathrm{~A}$ & $145,4 \mathrm{~A}$ & $143,4 \mathrm{~A}$ & & $17,0 \mathrm{~A}$ & $16,7 \mathrm{~A}$ & $17,0 \mathrm{~A}$ & \\
\hline CV (\%) & & 3,05 & & & & 5,20 & & \\
\hline
\end{tabular}

${ }_{1}$ DAS $=$ dias antes da semeadura da soja. Longit.= Longitudinal; Transv. $=$ Transversal; S. rol. $=$ Sem rolagem; NNHP: número de nós na haste principal da soja.

2 Médias seguidas da mesma letra minúscula, comparadas na coluna, e letra maiúscula, comparadas na linha, não diferem estatisticamente entre si pelo teste de Tukey $(P>0.05)$. 
A variável número de nós na haste principal da soja não foi influenciada pelos fatores manejo mecânico e químico da palha da aveia preta. A diferença de estatura apresentada pela soja quando do manejo químico ao 30 DAS em relação ao 15 DAS não propiciou aumento no número de nós na haste principal da soja, cultivar CD-205, possivelmente porque a diferença foi pequena devido ao baixíssimo coeficiente de variação, não evidenciando estiolamento da cultura (Tabela 4).

As variáveis número de vagens por planta na maturação fisiológica e stand final da cultura da soja, cultivar CD-205, não foram influenciadas pelos manejos químicos e mecânicos da aveia preta (Tabela 5). Entretanto, a regulagem da semeadora foi para distribuir 16 sementes por metro em espaçamento entre linhas de 0,45 m, assim, ter-se-ia consumido cerca de 355,56 mil sementes ha-1, o que resultou em aproximadamente 220 mil plantas ha-1, ou seja, perda de cerca de 135,56 sementes ha-1 $(38,13 \%)$.

Tabela 5. Número de vagens por planta na maturação fisiológica e stand final da cultura da soja, cv. CD-205, em função da época de dessecação e do tipo de rolagem da aveia preta. UEPG, Ponta Grossa-PR.

\begin{tabular}{|c|c|c|c|c|c|c|c|c|}
\hline \multirow{3}{*}{$\begin{array}{l}\text { Épocas de } \\
\text { Dessecação }\end{array}$} & \multicolumn{3}{|c|}{$\begin{array}{c}\text { Número de vagens por } \\
\text { planta }\end{array}$} & \multicolumn{4}{|c|}{ Stand final (mil plantas ha-1) } & \multirow{3}{*}{ MÉDIAS } \\
\hline & & Rolagen & & \multirow{2}{*}{ MÉDIAS } & \multicolumn{3}{|c|}{ Rolagem } & \\
\hline & Longit. & Transv. & Sem rol. & & Longit. & Transv. & Sem rol. & \\
\hline $30 \mathrm{DAS}^{1}$ & 86,19 & 96,06 & 86,06 & $89.44 \mathrm{a}$ & 222,21 & 201,93 & 220,36 & $214,84 \mathrm{a}$ \\
\hline 15 DAS & 77,88 & 98,31 & 98,44 & $91.55 \mathrm{a}$ & 220,65 & 216,85 & 219,01 & $218,84 \mathrm{a}$ \\
\hline 0 DAS & 77,71 & 77,00 & 83,44 & $79.38 \mathrm{a}$ & 216,70 & 233,47 & 229,74 & $226,64 \mathrm{a}$ \\
\hline MÉDIAS & $80,59 \mathrm{~A}$ & 90,46 & $89,31 \mathrm{~A}$ & & $219,86 \mathrm{~A}$ & $217,41 \mathrm{~A}$ & $223,04 \mathrm{~A}$ & \\
\hline CV (\%) & & 16,89 & & & & 9,95 & & \\
\hline
\end{tabular}

${ }^{1}$ DAS = dias antes da semeadura da soja. Longit.= Longitudinal; Transv. $=$ Transversal; Sem rol.= Sem rolagem.

${ }^{2}$ Médias seguidas da mesma letra minúscula, comparadas na coluna, e letra maiúscula, comparadas na linha, não diferem estatisticamente entre si pelo teste de Tukey $(P>0.05)$.

Não houve efeito significativo da época de dessecação e do tipo de rolagem da aveia preta sobre a massa de 1000 grãos (MMG), não obstante, houve efeito do fator tipo de rolagem da aveia preta sobre a produtividade da cultura da soja, cultivar CD-205 (Tabela 6). O coeficiente de variação para a variável MMG foi de 30,53\%, demonstraram baixa precisão experimental, o que segundo Pimentel Gomes (2009) demonstra baixa homogeneidade dos dados e alta variação ao acaso, dessa maneira, mesmo as diferenças sendo consideráveis, não foram significativas, principalmente quando do uso de diferentes 
tipos de rolagem da aveia preta. A MMG quando da rolagem longitudinal em relação à transversal e ausência de rolagem foi de 38,1 e 17,5 g inferior, ou seja, diferença de 26,28 e 14,07\%, respectivamente, diferença essa, não significativa pelo teste de comparação de médias utilizado (Tabela 6).

Tabela 6. Massa de 1000 grãos e produtividade da soja, cv. CD-205, em função da época de dessecação e do tipo de rolagem da aveia preta. UEPG, Ponta Grossa-PR.

\begin{tabular}{|c|c|c|c|c|c|c|c|c|}
\hline \multirow{3}{*}{$\begin{array}{l}\text { Épocas de } \\
\text { Dessecação }\end{array}$} & \multicolumn{3}{|c|}{ Massa de 1000 grãos (g) } & \multirow{3}{*}{ MÉDIAS } & \multicolumn{3}{|c|}{ Produtividade $\left(\mathrm{kg} \mathrm{ha}^{-1}\right)$} & \multirow{3}{*}{ MÉDIAS } \\
\hline & \multicolumn{3}{|c|}{ Rolagem } & & \multicolumn{3}{|c|}{ Rolagem } & \\
\hline & Longit. & Transv. & Sem rol. & & Longit. & Transv. & Sem rol. & \\
\hline $30 \mathrm{DAS}^{1}$ & 118,2 & 143,1 & 98,8 & $135,2 \mathrm{a}$ & $2.804,8$ & $2.945,0$ & $2.756,2$ & $2835,3 \mathrm{a}$ \\
\hline 15 DAS & 103,8 & 124,4 & 105,6 & $126,9 \mathrm{a}$ & $3.182,8$ & $3.193,0$ & $3.062,7$ & $3146,2 \mathrm{a}$ \\
\hline 0 DAS & 98,8 & 152,5 & 138,1 & $114,2 \mathrm{a}$ & $2.559,2$ & $2.868,8$ & $2.856,5$ & $2761,5 \mathrm{a}$ \\
\hline MÉDIAS & $106,9 \mathrm{~A}$ & $124,4 \mathrm{~A}$ & $145,0 \mathrm{~A}$ & & 2448,9B & $3002,2 \mathrm{~A}$ & $2891,8 \mathrm{~A}$ & \\
\hline CV (\%) & & 30,53 & & & & 15,77 & & \\
\hline
\end{tabular}

1 DAS = dias antes da semeadura da soja. Longit.= Longitudinal; Transv.= Transversal; Sem rol.= Sem rolagem.

2 Médias seguidas da mesma letra minúscula, comparadas na coluna, e letra maiúscula, comparadas na linha, não diferem estatisticamente entre si pelo teste de Tukey $(P>0.05)$.

A rolagem da aveia preta no sentido da linha de semeadura da soja (Longitudinal) influenciou negativamente a produtividade da cultura da soja, reduzindo-a em 18,43\% quando comparada à obtida com a rolagem transversal e 15,32\% sem rolar a aveia preta, correspondendo à redução de 553,3 e 442,9 kg ha-1, respectivamente (Tabela 6). A época de dessecação não interferiu significativamente na produtividade da cultura da soja, ainda assim, quando a dessecação foi realizada 15 DAS, a soja produziu 384,7 kg ha-1 (12,23\%) e $310,9 \mathrm{~kg}$ ha-1 (9,88\%) a mais que quando da dessecação ao 0 DAS e aos 30 DAS, respectivamente (Tabela 6). Diferentemente, Argenta et al. (2001) obtiveram aumento de 13,5\% na produtividade da cultura do milho quando da dessecação da aveia preta 15 DAS, entretanto, não detectaram influência do manejo da palha. Bortoluzzi; Eltz (2001) não lograram diferenças para a variável produtividade da cultura da soja em função do manejo da palhada da aveia preta quando do controle das plantas daninhas em pós-emergência, contudo, quando da ausência de controle das plantas daninhas em pós-emergência, quando da rolagem da palha houve redução de 18,2\% da produtividade da cultura da soja em relação à palha em pé, resultado este contraditório ao obtido neste estudo (Tabela 6), entretanto, os autores não citam o sentido de rolagem da palha de aveia preta. 
Para as condições em que o experimento foi conduzido, o resultado de produtividade infere que, a rolagem no sentido longitudinal não foi eficiente e que, o mais econômico talvez seja não rolar a aveia preta, pois além de reduzir os gastos com mão de obra, combustível, depreciação de equipamentos, contribui com a redução da compactação e desagregação do solo, podendo, no entanto, a dessecação ser realizada em qualquer uma das três épocas testadas. Todavia, observa-se que o manejo em época intermediária (15 DAS) foi mais efetivo, por permitir o estabelecimento da soja no limpo, reduzindo com isso, a probabilidade de novos fluxos de plantas daninhas durante a fase inicial de desenvolvimento da soja (NPD). Conjuntura constatada por Dirks et al. (2000) ao avaliarem duas safras consecutivas, onde a dessecação antecedendo a semeadura direta da soja propiciou melhor emergência e desenvolvimento inicial da cultura, consubstanciando-se em aumento da produtividade.

A média nacional de produtividade da soja na safra 2018/19 foi de $3.206 \mathrm{~kg}$ ha-1, apresentando previsão de pequeno aumento para a próxima safra (3.292 kg ha-1) (CONAB, 2019). Comparando-se com o maior valor médio alcançado para a variável neste estudo, $3.146,2 \mathrm{~kg}$ ha-1, obtido quando da dessecação da aveia preta aos 15 DAS, houve similaridade, entretanto, quando da rolagem no sentido longitudinal, a produtividade foi $23,62 \%$ inferior à média nacional na safra 2018/19, diferença esta de 757,1 kg ha-1 (Tabela $6)$.

O manejo mecânico da aveia preta afetou a cobertura do solo, a qual foi menor quando da rolagem no sentido longitudinal (Tabela 1), favorecendo, provavelmente 0 desenvolvimento das plantas daninhas, uma vez que, foi o tratamento que apresentou os maiores valores de massa fresca e seca de plantas daninhas (Tabela 3 ), reduzindo significativamente a produtividade da cultura da soja (Tabela 6). Assim, os manejos rolagem da palha de aveia preta no sentido transversal e ausência de rolagem apresentaram efeito supressivo sobre o desenvolvimento das plantas daninhas, denotado pelos baixos valores de MFPD e MSPD (Tabela 3), o que supostamente permitiu menor competição interespecífica e maior produtividade da cultura da soja, cultivar CD-205 (Tabela 6).

\section{CONCLUSÕES}

A dessecação da aveia preta aos 15 dias antes da semeadura da soja reduziu o número de plantas daninhas emergidas por unidade de área.

O teor de água no solo e a estatura da cultura da soja em R7 foram maiores quando 
da realização da dessecação da aveia preta aos 30 DAS.

A rolagem da palha de aveia preta no sentido transversal e ausência de rolagem aumentaram a cobertura do solo, reduzindo a massa fresca e seca de plantas daninhas, resultando, respectivamente, em aumento de 553,3 e 442,9 kg ha-1 na produtividade da soja em relação à rolagem no sentido Longitudinal.

\section{REFERÊNCIAS}

ARGENTA, G.; SILVA, P.R.F.; FLECK, N.G.; BORTOLLINI, C.G.; NEVES R.; AGOSTINETTO, C., Efeitos do manejo mecânico e químico na aveia-preta no milho em sucessão e controle de capim papuã. Pesquisa Agropecuária Brasileira, v. 36, n.6, p.851-860, 2001.

BLANCO, H.G.; BLANCO, F.M.G. Efeito do manejo do solo na emergência de plantas daninhas anuais. Pesquisa Agropecuária Brasileira, v.26, n.2, p.215-220, 1991.

BOLLER, W.; CALDATO, D.E. Desenvolvimento da cultura do feijão (Phaseolus vulgaris L.) em diferentes condições de cobertura e de preparo do solo. Engenharia Agrícola, v.21, n.2, p.167-173, 2001.

BORGES, W.L.B.; FREITAS, R.S.; MATEUS, G.P.; SÁ, M.E.; ALVES, M.C. Supressão de plantas daninhas utilizando plantas de cobertura do solo. Planta Daninha, v.32, n.4, p.755763, 2014.

BORTOLUZZI, E.C.; ELTZ, F.L.F. Efeito do manejo mecânico da palhada de aveia preta sobre a cobertura, temperatura, teor de água no solo e emergência da soja em sistema plantio direto. Revista Brasileira de Ciência do Solo, v.24, n.2, p.449-457. 2000.

BORTOLUZZI, E.C.; ELTZ, F.L.F. Manejo da palha de aveia preta sobre as plantas daninhas e rendimento de soja em semeadura direta. Ciência Rural, v.31, n.2, p.237-243, 2001.

CERETTA, C.A.; BASSO, C.J.; HERBES, M.G.; POLETTO, N.; SILVEIRA, M.J. Produção e decomposição de fitomassa de plantas invernais de cobertura de solo e milho, sob diferentes manejos da adubação nitrogenada. Ciência Rural, v.32, p.49-54, 2002. 
CONAB-COMPANHIA NACIONAL DE ABASTECIMENTO. Acompanhamento de safra brasileira: grãos. Brasília, DF: Conab, 2019. Décimo segundo Levantamento - V.6 - Safra 2018/19 - N.12. Disponível em: https://www.conab.gov.br/info-agro/safras. Acesso em: 13 de outubro de 2019.

CUNHA, M.M. da; FLECK, N.G.; VARGAS, L. Interferência de papuã (Brachiaria plantaginea (Linck) Hitchc.) e de espécies daninhas dicotiledôneas em soja. Pesquisa Agropecuária Gaúcha, v.3, n.2, p.125-131,1997.

DIRKS, J.T.; JOHNSON, W.G.; SMEDA, R.J.; WIEBOLD, W.J. Reduced rates of sulfentrazone plus chlorimuron and glyphosate in no-till, narrow-row, glyphosate resistance Glycine max. Weed Science, v.48, n.5, p.618-627, 2000.

DURIGAN, J.C.; FILHO, R.V.; MATUO, T.; PITELLI, R.A. Períodos de matocompetição na cultura da soja (Glycine max (L.) Merril), cultivares Santa Rosa e IAC - 2.1 - Efeitos sobre os parâmetros de produção. Planta Daninha, Brasília, v.1, n.2, p.86-100, 1983.

EMBRAPA-Empresa Brasileira de Pesquisa Agropecuária. Sistema Brasileiro de Classificação de Solos. 2.ed. Rio de Janeiro: Embrapa Solos, 2006. 306 p.

LEITE, D.M.; VIEIRA, L.B.; FERNANDES, H.C.; CARNEIRO, J.E.S.; RISSO, L.F.C. Desempenho da cultura do feijão em função de diferentes sistemas de cultivo. Engenharia na agricultura, v.21, n.6, p.539-546, 2013.

LORENZI, H. Manual de identificação e controle de plantas daninhas: plantio direto e convencional. Nova Odessa: Plantarum, 2006. 336p.

MAGUIRE, J.D. Speed of germination-aid in selection and evaluation for seedling emergence and vigor. Crop Science, v.2, n.1, p.176-177, 1962.

NEPOMUCENO, M.; ALVES, P.L.C.A.; DIAS, T.C.S.; PAVANI, M.C.M.D. Períodos de interferência das plantas daninhas na cultura da soja nos sistemas de semeadura direta e convencional. Planta daninha. v.25, n.1, p.43-50. 2007. 
PEEL, M.C.; FINLAYSON, B.L.; MCMAHON, T.A. Updated world map of the Köppen-Geiger climate classification. Hydrology and Earth System Sciences Discussions, v.11, p.16331644, 2007. https://doi.org/10.5194/hess-11-1633-2007, 2007.

PIMENTEL GOMES, F.P. Curso de Estatística Experimental. 15aㅡ Ed., Livraria Nobel S.A., São Paulo. 2009. 451p.

PITELLI, R.A. O termo planta-daninha. Planta daninha, v.33, n.3, p.622-623. 2015.

RIQUETTI, N.B.; SOUSA, S.F.G. de; TAVARES, L.A.F.; CORREIA, T.P. da S.; SILVA, P.R.A.; BENEZ, S.H. Diferentes manejos da palha de aveia preta na produtividade de milho em plantio direto. Revista Científica Eletrônica de Agronomia, v.22, n.2, p.1-8, 2012.

RIZZARDI, M.A.; FLECK, N.G.; RIBOLDI, J.; AGOSTINETTO, D. Ajuste de modelo para quantificar o efeito de plantas daninhas e época de semeadura no rendimento da soja. Pesquisa Agropecuária Brasileira, v.38, n.1, p.35-43, 2003.

RIZZARDI, M.A.; ROMAM, E.S.; BOROWSKI, D.Z.; MARCON, R. Interferência de populações de Euphorbia heterophylla e Ipomea ramosissima isoladas ou em misturas sobre a cultura da soja. Planta daninha, v.22 n.1, p.29-34, 2004

RUEDELL, J. Plantio direto na região de Cruz Alta. Convênio FUNDACEP/BASF. 19851994. Cruz Alta, RS: Fundação Centro de Experimentação e Pesquisa Fecotrigo FUNDACEP, 1994. Controle de plantas daninhas: p.40-82.

SANTOS, D. dos; SOUZA, E.G. de; NÓBREGA, L.H.P.; BAZZI, C.L.; QUEIROZ, F.N. de.. Physical properties of soils and soybean yields after planting cover crops. Engenharia Agrícola, v.35, n.2, p.280-292, 2015.

SILVA, F. de A.S.; AZEVEDO, C.A.V. de. Principal Components Analysis in the Software Assistat-Statistical Attendance. In: World Congress on Computers in Agriculture, 7, RenoNV-USA: American Society of Agricultural and Biological Engineers, 2009.

USDA - United States Department of Agriculture. Foreign Agricultural Service (FAS). Grain: 
world mar-kets and trade. United States: USDA/FAS, nov. 2019. Disponível em: <https://apps.fas.usda.gov/psdon-line/circulars/grain.pdf>. Acesso em: 06 jun. 2019.

VIDAL, R.A.; MEROTTO Jr., A. Herbicidologia. Porto Alegre: Evangraf, 2001. 152p.

VOLL, E.; GAZZIERO, D.L.P.; BRIGHENTI, A.A.M.; ADEGAS, F.S. Competição relativa de espécies de plantas daninhas com dois cultivares de soja. Planta Daninha, v.20, n.1, p.1724, 2002. 